\title{
Notes sur le temps de Don Quichotte, ses aventures, ses métamorphoses
}

\section{Lucien Castela}

\section{(2) OpenEdition}

1 Journals

\section{Édition électronique}

URL : https://journals.openedition.org/cher/4154

DOI : $10.4000 /$ cher.4154

ISSN : 2803-5992

\section{Éditeur}

Presses universitaires de Strasbourg

\section{Édition imprimée}

Date de publication : 30 novembre 2021

Pagination : 27-28

ISBN : 979-10-344-0095-9

ISSN : 1968-035X

\section{Référence électronique}

Lucien Castela, « Notes sur le temps de Don Quichotte, ses aventures, ses métamorphoses », reCHERches [En ligne], 27 | 2021, mis en ligne le 30 novembre 2021, consulté le 12 janvier 2022. URL : http://journals.openedition.org/cher/4154 ; DOI : https://doi.org/10.4000/cher.4154

\section{(c) (i) (ㅇ)}

Ce(tte) œuvre est mise à disposition selon les termes de la Licence Creative Commons Attribution Pas d'Utilisation Commerciale - Partage dans les Mêmes Conditions 4.0 International. 


\title{
Notes sur le temps de Don Quichotte, ses aventures, ses métamorphoses
}

\author{
LUCIEn CAstela*
}

Il accompagne le dire, murit avec l'écrire et trouve sa forme dans le lire. Lucien Castela

$\mathrm{L}$ e $\mathrm{XVI}^{\mathrm{e}}$ siècle est une période de transformations. Les idées venues surtout d'Italie offrent à la société une vision différente du monde. Les valeurs traditionnelles, sans être éliminées, sont progressivement remplacées par des réflexions nouvelles. La place de l'homme dans la société se fait plus complexe, tandis que le temps coule parfois sur d'autres pentes que celles que la religion avait fixées. Des espaces nouveaux s'ouvrent et font découvrir une géographie renouvelée. Le temps reçoit l'influence de la découverte de l'espace : on sait désormais que toutes ces constructions sont fragiles et que le choc de Lépante aurait pu engager le monde sur des coordonnées très différentes.

Désormais, la vérité ne peut être que partielle ou parfois contradictoire.

Il y a dans le livre une approche de faits surprenants qui confirment la richesse multiple des aventures : celles-ci ne sont que des exemples qui cherchent à évoquer une construction inachevée et toujours plus complexe, dont il est impossible d'avoir une conscience globale.

Cervantes dans son récit du Don Quichotte, surtout dans la deuxième partie, mêle le faux, l'imaginaire, le théâtral à la réalité du quotidien pris en exemple dans telle ou telle aventure. Le vide, qui pourrait se remplir, se dévoile parfois, même si cette découverte laisse la possibilité à la naissance d'une aventure.

$\mathrm{Au}$ croisement des routes et des idées $\mathrm{du} \mathrm{XvI}^{\mathrm{e}}$ siècle, Cervantes est avant tout un homme issu de la petite bourgeoisie d'origine juive dont les rescapés locaux sont convertis de force. Sa famille est installée à Alcalá de Henares où il passe son enfance. Il reçoit une bonne éducation qui, selon ses vœux, devait lui permettre de devenir soldat. Il y a dans le Don Quichotte un épisode très

Lucien Castela, professeur des universités, émérite de l'Université de Provence 
court dans lequel Don Quichotte et Sancho rencontrent un jeune homme qui se dépêche de rejoindre le port où il pense s'embarquer et s'enrôler dans les troupes qui combattent en Italie. Cervantes évoque là un souvenir de jeunesse. En Italie, il prit part à la Bataille de Lépante (1571) au cours de laquelle il fut blessé et perdit l'usage d'un bras. Soigné en Sicile, il récupéra et une galère devait le transporter à Valence. Des pirates algérois arraisonnèrent la galère et Cervantes resta prisonnier pendant quatre ans. Racheté par les moines de La Merci, il put regagner l'Espagne où une vie de pauvreté, de petits métiers l'attendait.

Le spectacle de la société espagnole est alors la base de ses compositions littéraires. Son héros, Don Quichotte, naît dans une prison et désormais la force du rêve l'emporte dans sa création.

Dans le premier chapitre, Don Quichotte fait état de quantité de romans de chevalerie dont il tire ses règles de vie et imagine le monde régi par quelque enchanteur.

Cervantes utilise essentiellement l'opposition entre la règle, le devoir et les principes ainsi que leurs contradictions. D'autres éléments viennent à son secours en particulier la paréidolie, le déguisement et la substitution du trivial par le céleste.

Les aventures de Don Quichotte sont conditionnées par les variations du temps. Le temps de l'exil est un temps arrêté dans lequel les participants évoquent des thèmes tournant autour de l'emprisonnement, la perte de la liberté, l'exil, l'esclavage... Souvent, certains d'entre eux sont revus et apparaissent comme des contraires (la liberté de la condition féminine).

Cervantes se plaît à renverser certains sujets, comme dans les épisodes avec Roque Guinard. Il n'hésite pas à aborder des thèmes triviaux et à mélanger les plans. Le temps, alors, est celui de l'actualité, des problèmes qui éclatent à Barcelone par exemple, auxquels se mêlent les inventions du rêve. Le mélange entre ces phénomènes politiques et historiques fait partie d'une illustration temporaire des interprétations qui s'offrent à nous. Le temps est alors éclaté et le désordre du monde remplace la simplicité du passé. Avec Jean Christophe Saladin dans Les aventures de la mémoire perdue, Pascal Quignard dans L'homme aux trois lettres frôle et parfois pénètre dans le mystère du "dire ». Traces de jadis dans l'actuel. Nous ne sommes pas venus de nous-mêmes. La trace est notre part d'éternité. 